\title{
Isolation and Identification of Compounds from the Leaf Extract of Melaleuca alternifolia
}

\author{
Gagan Shah ${ }^{1 *}$, Dhandeep Singh ${ }^{2}$, Uttam Singh Baghel ${ }^{3}$
}

\section{Gagan Shah ${ }^{1 *}$, Dhandeep Singh ${ }^{2}$, Uttam Singh Baghel $^{3}$}

'Department of Pharmaceutical Sciences, IKG Punjab Technical University, Kapurthala, Punjab, INDIA.

${ }^{2}$ Department of Pharmaceutical Sciences and Drug Research Punjabi University, Patiala, Punjab, INDIA. ${ }^{3}$ Department of Pharmaceutical Analysis, Khalsa College of Pharmacy, Amritsar, Punjab, INDIA.

\section{Correspondence}

Gagan Shah

Department of Pharmaceutical Sciences, IKG Punjab Technical University, Kapurthala, Punjab, INDIA.

Phone no: +91-9814616627

E-mail: gaganshah83@gmail.com

History

- Submission Date: 25-07-2017;

- Review completed: 11-09-2017:

- Accepted Date: 02-11-2017

DOI : 10.5530/pj.2017.6s.157

Article Available online

http://www.phcogj.com/v9/i6s

Copyright

(C) 2017 Phcog.Net. This is an openaccess article distributed under the terms of the Creative Commons Attribution 4.0 International license.

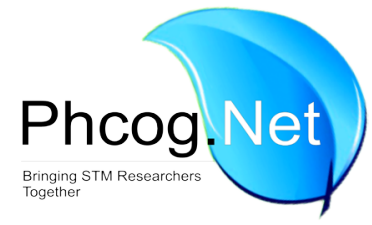

\begin{abstract}
Introduction: Melaleuca alternifolia also known as Tea tree oil belonging to family Myrtaceae. This plant has diverse and therapeutic uses in traditional herbal medicine for treating Skin care, First Aid, Household Cleaning, Hair care, Aromatherapy, Feminine care, Chronic illness, and Dental care in Australia. Method: The methanolic extract of Melaleuca alternifolia family Myrtaceae was subjected for Soxhlet extraction in round bottomed flask with petroleum ether. The petroleum ether extracted leaf powder was dried and once again subjected to Soxhlet extraction successively with different solvents viz, chloroform, ethyl acetate and methanol. Result: The IR spectra showed characteristic absorption bands at $3421 \mathrm{~cm}^{-1}$ indicating the presence of a $\mathrm{OH}$ group, at $1691 \mathrm{~cm}^{-1}$ for $\mathrm{C}=\mathrm{O}$ group, $2848 \mathrm{~cm}^{-1}$. The ${ }^{1} \mathrm{HNMR}$ spectra showed a triplet signal at $\delta 10.44,9.48,13.21$ showing the presence of $\mathrm{OH}$ group and Carboxylic acid. The ${ }^{13} \mathrm{C}$ NMR spectra showed signals at $\delta 16.28$ for a methyl carbon, $\delta 29.89$ for a methylene carbon, The ESI-negative mode mass spectrum showed pseudo molecular ions at m/z 515 for $[\mathrm{M}+]$ ion. Conclusion: Based on spectral analysis and comparison of the spectral data with literature values, the compounds were identified as 3,3'dimethylellagic acid and its aglycone portion with some little impurity.
\end{abstract}

Key words: Methalonic, Myrtaceae, Melaleuca alternifolia, 3, 3'dimethylellagic acid, Aromatherapy, Chloroform.

\section{INTRODUCTION}

Melaleuca alternifolia is likewise called tea tree oil (TTO), the unstable fundamental oil got principally from the Australian local plant. Utilized for its antimicrobial properties, TTO is utilized as the dynamic fixing in numerous plans used to treat cutaneous contaminations. Melaleuca alternifolia accessible over the counter in Australia, Europe, and North America and is promoted as a solution for different sicknesses. ${ }^{1}$ This plant is essential for therapeutic uses and herbal products. The leaves of "tea trees" were utilized for the treatment of hack or were spread on wounds, ${ }^{2}$ and tea tree leaves were drenched to make a mixture for treatment of sore throats or skin illnesses. ${ }^{3}$

Tea Tree oil is an active ingredient of many topical preparations for the treatment of cutaneous infections including wound infections ${ }^{4}$ fungal dermatoses, ${ }^{5}$ otitis media, ${ }^{6}$ and acne. ${ }^{7}$ Although several clinical studies suggest that tea tree oil possesses antimicrobial activity. Melaleuca alternifolia is consisting of terpene hydrocarbons, which contain monoterpenes, sesquiterpenes, and their associated alcohols. Brophy and colleagues ${ }^{8}$ examined over 800 Tea Tree oil samples by gas chromatography and GC-MS and report approximate 100 components and their Percentage composition in Table 1.

The bark and stem of Melaleuca alternifolia(Myrtaceae) led to the isolation and identification of 3,3' dimeth-

Cite this article: Shah G, Baghel US, singh D. Isolation and Identification of Compounds from the Leaf Extract of Melaleuca alternifolia. Pharmacog J. 2017;9(6)Suppl:s52-s5. ylellagicacid and five pentacyclic triterpenes: 23 trihydroxyolean12en28oic acid (arjunolic acid) 3 Bhydroxylup20 (29) en27,28dioic acid (melaleucic acid), Betulinic acid, betuline, $3 \beta$-theacetylurs12en28oicacid and the mixture of fatty acids and esters, and several hydrocarbons. ${ }^{9}$

\section{MATERIAL AND METHOD}

\section{Collection and authentication of plant material}

The leaves of Melaleuca alternifolia (Myrtaceae) were collected from the hills of the Nilgiris district of Tamil Nadu, India in January 2016 from the healthy plants. The herbarium was prepared by using plant material and Dr. K. Madhava Chetty (Assistant Professor, Department of Botany, Sri Venkateshwara University, Tirupati, Andhra Pradesh, India) authenticated the plant under voucher specimen no.1241, dated May 28, 2016. A voucher specimen of plant material has been retained in the Department of Pharmacognosy and Phyto chemistry, IKG Punjab Technical University, Kapurthala, Punjab, India.

\section{Extraction and isolation procedure}

\section{a. Crude Extraction}

The plant Melaleuca alternifolia Leaf powder (1600 g) was subjected for Soxhlet extraction in round bot- 
Table 1: Composition of M. alternifolia (tea tree) oil.

\begin{tabular}{cc}
\hline Component & Typical Composition (\%) \\
\hline Terpinen-4-ol & 40.1 \\
$\gamma$ Terpinene & 23.0 \\
$\alpha$-Terpinene & 10.4 \\
1,8-Cineole & 5.1 \\
Terpinolene & 3.1 \\
p-Cymene & 2.9 \\
$\alpha$-pinene & 2.6 \\
$\alpha$-Terpineol & 2.4 \\
Aromadendrene & 1.5 \\
$\delta$-Cadinene & 1.3 \\
Limonene & 1.0 \\
$\beta$-phellandrene & 0.9 \\
Globulol & 0.8 \\
myrcene & 0.8 \\
$\alpha$-thujene & 0.8 \\
$\beta$-pinene & 0.6 \\
sabinene & 0.4 \\
$\alpha$-phellandrene & 0.4 \\
Viridiflorol & 0.3 \\
\hline
\end{tabular}

tomed flask with methanol (12.5 lts) for $12 \mathrm{~h}$. The extract was concentrated under reduced pressure at $50-60^{\circ} \mathrm{C}$ till complete drying. The dried crude methanolic extract of the plant (yield $347 \mathrm{~g}, 21.68 \%$ ) was stored in a closed vessel at $4^{\circ} \mathrm{C}$.

\section{b. Successive extraction}

The methanolic extract ( $347 \mathrm{~g}$ ) was subjected for Soxhlet extraction in round bottomed flask with petroleum ether $(2.0 \mathrm{lts})$ for $12 \mathrm{~h}$. The extract was concentrated under reduced pressure at $50-60^{\circ} \mathrm{C}$ till complete drying. The dried successive petroleum ether extract (yield 20 g, 5.76\%) was stored in a closed vessel at $4^{\circ} \mathrm{C}$ in a refrigerator till further use.

The petroleum ether extracted leaf powder was dried and once again subjected to Soxhlet extraction successively with different solvents viz, chloroform, ethyl acetate and methanol (2.0 lts each). The extracts were concentrated and stored as described above. Yields, successive chloroform extract, $38 \mathrm{~g}, 10.95 \%$, successive ethyl acetate extract, $28 \mathrm{~g}, 8.06 \%$ and successive methanol extraction $54 \mathrm{~g}, 15.54 \%$. The yields were calculated in percentage with reference to the air-dried drug. The successive extracts were stored in closed vessels at $4^{\circ} \mathrm{C}$ in a refrigerator till further use.

\section{Isolation of medicinal compound from Chloroform Fraction}

I. Adsorbing the chloroform extract to Silica gel

1. Add about $5 \mathrm{~g}$ of silica gel (for column chromatography 60-120 mesh) to the crude extract.

2. Gently heat the mixture using a hair dryer until the silica gel becomes free flowing.

II. Packing the Column for Chromatography

1. Take a cylindrical glass column and plug in a small piece of cotton.

2. Mount the column on the stand.

3. Take $25 \mathrm{~g}$ of fresh silica gel (for column chromatography 60-120 mesh) in a $250-\mathrm{ml}$ beaker.
4. Pour $100 \mathrm{~mL}$ of petroleum ether into the beaker and stir well using a glass rod to make slurry of the silica.

5. Pour the slurry into the column

6. Place a conical flask below the mounted column and drain out the excess solvent (petroleum ether).

7. Close the stop cock when the level of the solvent reaches just above the settled silica gel.

III. Loading the Crude material on to the Column

1. Total $38 \mathrm{gm}$ of Chloroform fraction was loaded in column.

2. Column runs with different solvents systems to collect fraction of that solvent with ratio of petroleum ether and chloroform (100, 75:25, 50:50 and 25:75).

3. Further continuation with ratio of Chloroform and Ethyl Acetate (100, 75:25, 50:50 and 25:75).

4. Further continuation with ratio of Ethyl Acetate and Acetone (100, $75: 25,50: 50$ and 25:75).

5. Further continuation with ratio of Acetone and Methanol (100, 75:25, 50:50 and 25:75).

6. Ratio of Chloroform and Ethyl Acetate fraction that is (100, 75:25, 50:50 and 25:75).

7. Elution was collected in a different beaker than dried and weighed.

IV. Washing of dried elute

1. The solid obtained in Chloroform and Ethyl Acetate (50:50) ratio washed with hexane to remove minor compounds.

2. Hexane insoluble compound was treated with charcoal to remove colour part.

3. Precipitation then filtered by using Whatman filter paper. The obtained solid dried compound was weighed (30 mg) and stored.

\section{TLC Studies}

Extract: $1 \mathrm{mg} / \mathrm{ml}$ in Ethyl acetate

The sample was dissolved in Ethyl acetate and filtered before spotting the sample.

\section{RESULTS AND DISCUSSION}

\section{Spectral report for the compound}

The IR spectra showed characteristic absorption bands at $3421 \mathrm{~cm}^{-1}$ indicating the presence of a OH group, at $1691 \mathrm{~cm}^{-1}$ for $\mathrm{C}=\mathrm{O}$ group, $2848 \mathrm{~cm}^{-1}$

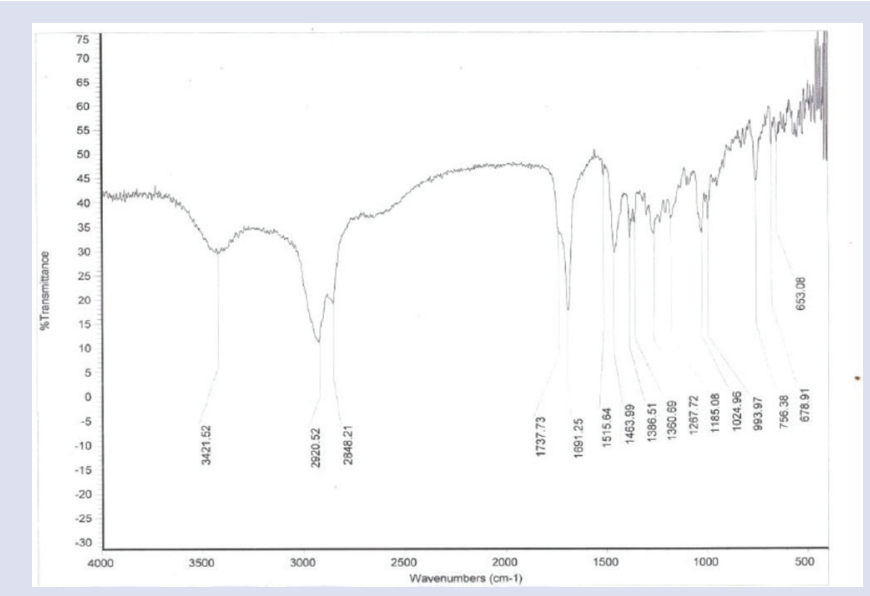

Figure 1: IR SPECTRA. 
(stretching frequency) and at 1463 and at $1386 \mathrm{~cm}-1$ for $\mathrm{C}-\mathrm{H}$ group (bending frequency) and at $1024 \mathrm{~cm}^{-1}$ for C-O group Figure 1.

The ${ }^{1} \mathrm{H}$ NMR spectra showed a triplet signal at $\delta 10.44,9.48,13.21$ showing the presence of $\mathrm{OH}$ group and Carboxylic acid. The signal at $\delta 7.27$ shows the presence of 2 Aromatic ring and signal at 3.71 shows the presence of $2 \mathrm{CH}$ group Figure 2.

The ${ }^{13} \mathrm{C}$ NMR spectra showed signals at $\delta 16.28$ for a methyl carbon, $\delta 29.89$ for a methylene carbon, $\delta 49.27$ for a methylene carbon under nitrogen function, a bunch of signals between 115.40 and 145.31 for aromatic carbon atoms.

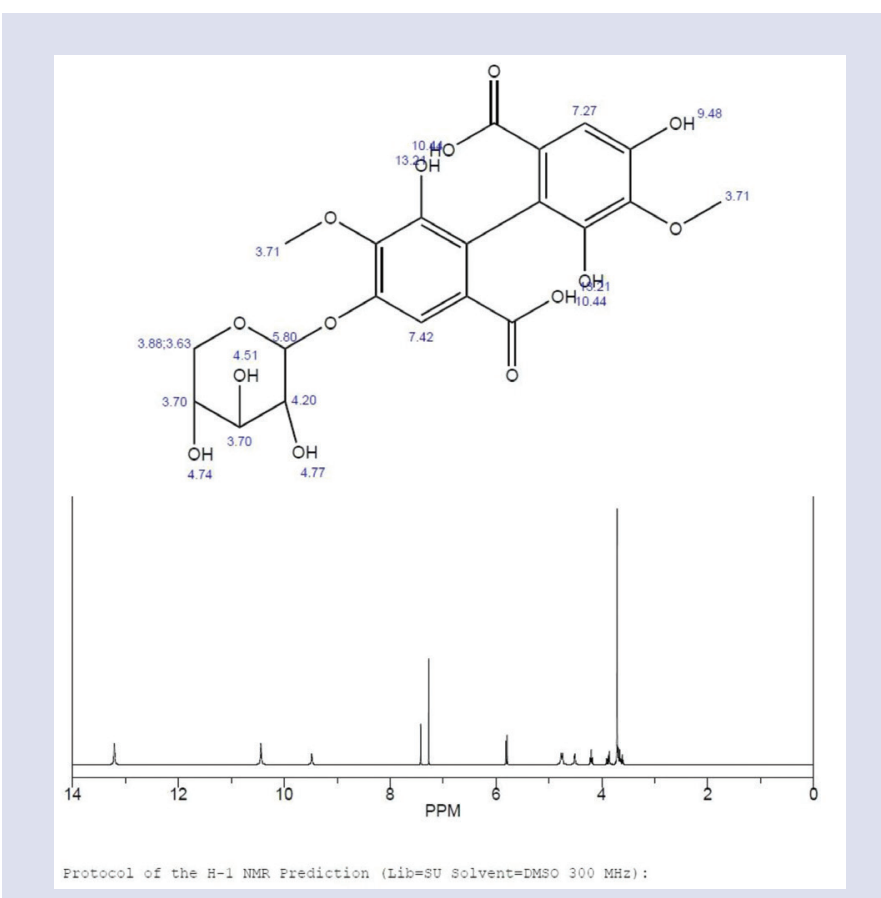

Figure 2: ChemNMR 1h Estimation.

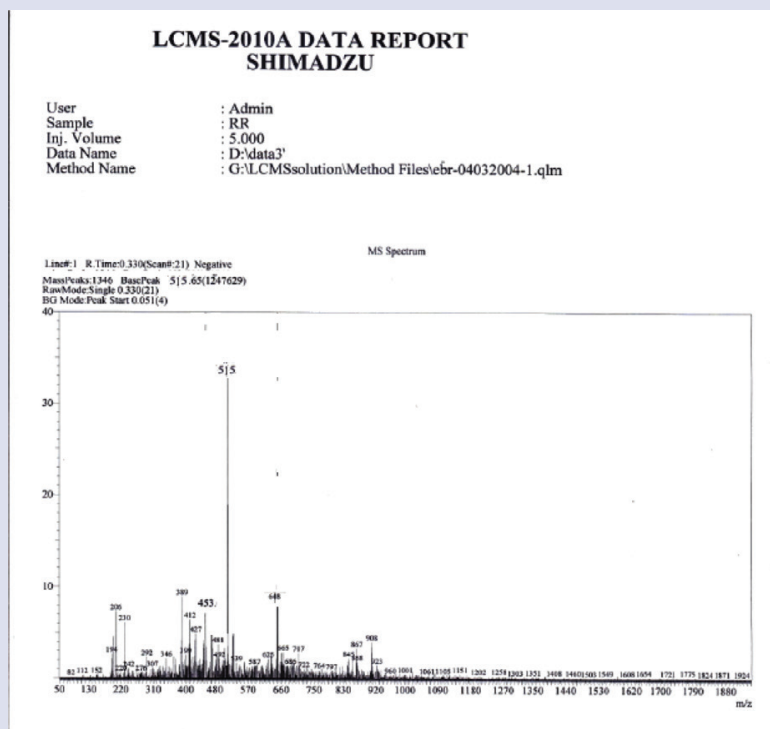

Figure 3: LC-MS SPECTRA.
The ESI-negative mode mass spectrum showed pseudo molecular ions at $\mathrm{m} / \mathrm{z} 515$ for $[\mathrm{M}+]$ ion. The ESI-positive mode mass spectrum showed pseudo molecular ions at $\mathrm{m} / \mathrm{z} 515[\mathrm{M}+\mathrm{Na}]+$ ion suggesting a molecular weight of 515 Figure 3.

IR-3421 cm $\mathrm{cm}^{-1}, 1691 \mathrm{~cm}^{-1}, 1024 \mathrm{~cm}^{-1}$.

${ }^{1} \mathrm{H}$ NMR (300 MHz, DMSO-d6): $\delta=10.44,9.48,13.21(6 \mathrm{OH}$, $\mathrm{j}=18,22,16,17.15,21), \delta=7.27(2 \mathrm{CH} \mathrm{J}=12,3), \delta=3.71(2 \mathrm{CH} 3, \mathrm{~J}=24,26)$

${ }^{13} \mathrm{C}$ NMR (126 MHz, DMSO-d6) $\delta=114.3$ (C-1), 140.9 (C-2), 141.8 (C-3), 151.4 (C-4), 111.9 (C-5), 112.8 (C-6), 158.4 (C-7), 111.8 (C-1), 141.6 (C-2), 140.4 (C-3), 153.0 (C-4), 111.8 (C-5), 110.6 (C-6), 158.5 (C-7), 61.6 (3-OCH3), 60.9 (3-OCH3), 101.4 (C-1"), 73.3 (C-2"), 76.5 (C-3"), 69.5 (C-4”), 77.3 (C-5”), 60.6 (C-6”). Đ ESI-IT-MS (positive ion mode, $40 \mathrm{~V}): \mathrm{m} / \mathrm{z}=515.0805[\mathrm{M}+\mathrm{Na}]+(100)$, calcd. 515.0801. Compound was identified as 3,3-di-O-methylellagic acid-4-O--d-glucopyranoside. The structure of the isolated compound shown in Figure 4.

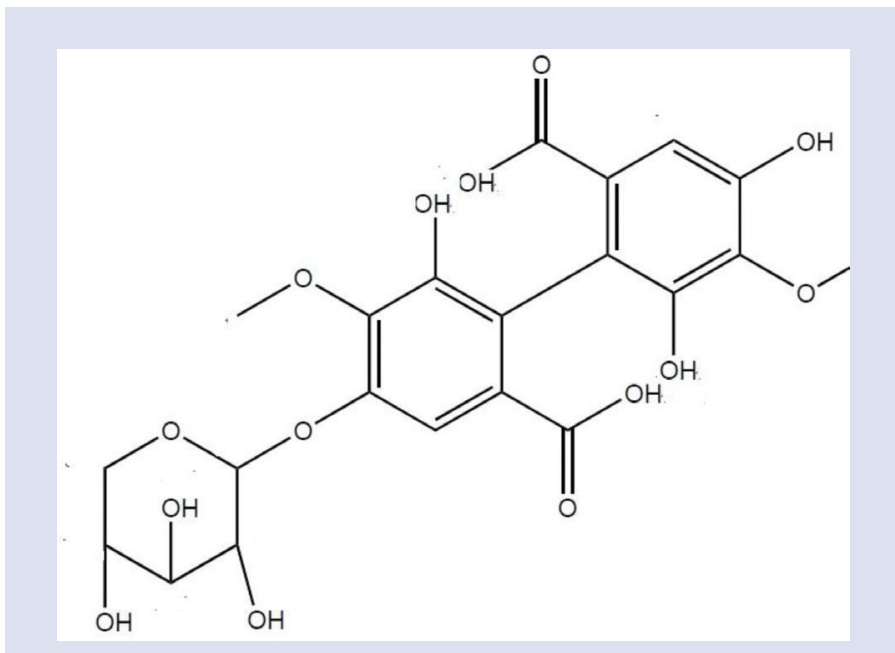

Figure 4: 3,3-di-O-methylellagic acid-4-O--d-glucopyranoside.

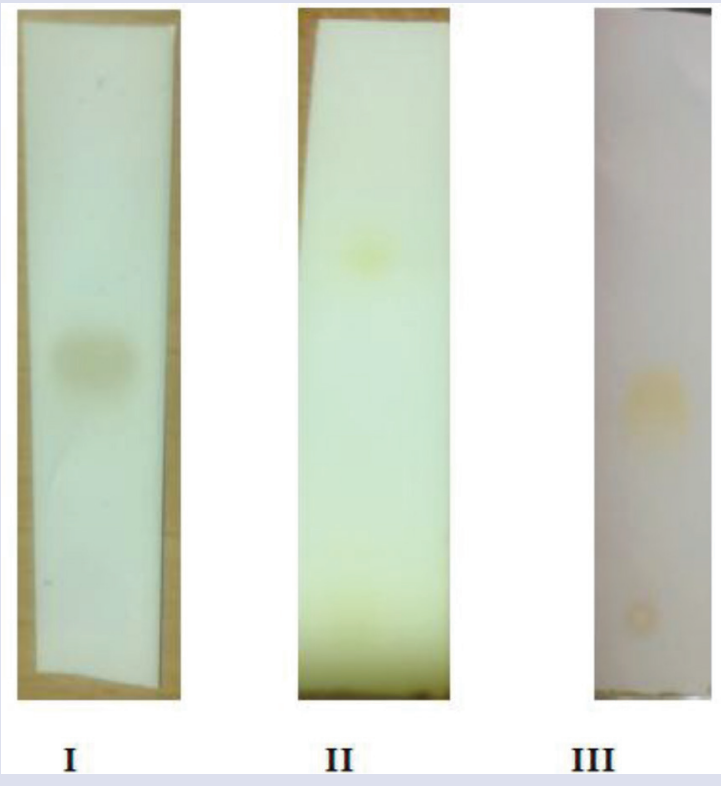

Figure 5: TLC Plates. 


\section{Tlc studies}

The sample was dissolved in Ethyl acetate and filtered before spotting the sample. Figure 5.

Chamber Saturation time: $30 \mathrm{~min}$.

\section{Rf Value}

Distance travelled by solute

Distance travelled by Solvent

\begin{tabular}{cccc}
\hline SI.No. & Solvent mobile phase & Ratio in $\mathrm{ml}$ & Rf Value \\
\hline I & Chloroform: Acetone & $4: 1.5$ & 0.48 \\
II & Chloroform: Ethyl acetate & $3.5: 1.5$ & 0.69 \\
III & DiChloroform: Acetone & $4.0: 1.0$ & 0.51 \\
\hline
\end{tabular}

\section{CONCLUSION}

Based on spectral analysis the compounds were identified as 3,3-diO-methylellagic acid-4-O--d-glucopyranoside portion with some little impurity.

\section{CONFLICTS OF INTEREST}

The authors are declared that there is no conflict of interest.

\section{ABBREVIATIONS USED}

NMR-Nuclear Magnetic Resonance Spectroscopy, IR-Infrared Spectroscopy, LC-MS-Liquid Chromatography-Mass Spectrometry.

\section{REFERENCES}

1. Carson CF, Hammer KA, Riley TV. Melaleuca alternifolia (Tea Tree) Oil: A Review of Antimicrobial and Other Medicinal Properties. Clinical Microbiology Reviews. 2006;19(1):50-62.

2. Shemesh A, Mayo WL. Australian tea tree oil: a natural antiseptic and fungicidal agent. Aust. J. Pharm. 1991;72:802-3

3. Low T. Bush medicine. Harper Collins Publishers, North Ryde,NSW, Australia 1990.

4. Halcon L, Milkus K. Staphylococcus aureus and wounds: A review of tea tree oil as prominising antimicrobial. Am J Infect control. 2004;32(7):402-8

5. Buck DS, Nidorf DM, Addino JG. Comparison of two topical preparations for the treatment of onychomycosis: Melaleuca alternifolia (tea tree) oil and clotrimazole. J Farm Practice. 1994;38(6):601-5

6. Farnan TB, McCallum J, Awa A, Khan AD, Hall SJ. Tea tree oil: in vitro efficacy in otitis sczema. J Laryngology Otol. 2005;119(3):198-201.

7. Bassett IB, Pannowitz DL, Barnetson RS. A comparative study of Tea tree oil versus benzyl peroxide in the treatment of acne. Med J Aust. 1990;153(8):455-8

8. Brophy JJ, Davies NW, Southwell IA, Stiff 1A, Williams LR. Gas chromatographic quality control for oil of Melaleucaterpinen-4-ol type (Australian tea tree). J. Agric. Food Chem. 1989;37(5):1330-5.

9. Tatiana RV, Luiz CA, Célia RA, Vanderlúcia FP, Evandro AN. Chemical constituents from Melaleuca alternifolia (Myrtaceae). Chemical New. 2004;27(4):1-6.
GRAPHICAL ABSTRACT

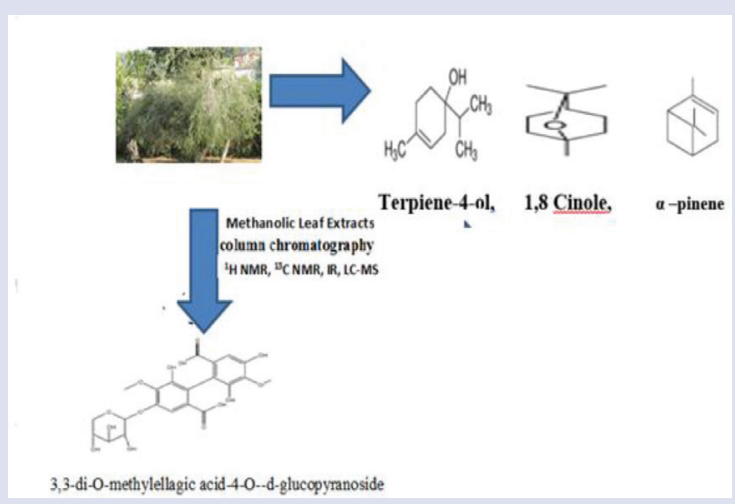

ABOUT AUTHORS

\section{SUMMARY}

The IR spectra showed characteristic absorption bands at 3421 $\mathrm{cm}-1$ indicating the presence of a $\mathrm{OH}$ group, at $1691 \mathrm{~cm}-1$ for $\mathrm{C}=\mathrm{O}$ group, $2848 \mathrm{~cm}-1$ (stretching frequency) and at 1463 and at $1386 \mathrm{~cm}-1$ for $\mathrm{C}-\mathrm{H}$ group (bending frequency) and at $1024 \mathrm{~cm}-1$ for $\mathrm{C}-\mathrm{O}$ group. The $1 \mathrm{H}$ NMR spectra showed a triplet signal at $\delta 10.44,9.48,13.21$ showing the presence of $\mathrm{OH}$ group and Carboxylic acid. The signal at $\delta 7.27$ shows the presence of 2 Aromatic ring and signal at 3.71 shows the presence of $2 \mathrm{CH}$ group. The ${ }^{13} \mathrm{C}$ NMR spectra showed signals at $\delta 16.28$ for a methyl carbon, $\delta 29.89$ for a methylene carbon, $\delta 49.27$ for a methylene carbon under nitrogen function, a bunch of signals between 115.40 and 145.31 for aromatic carbon atoms. The ESI-negative mode mass spectrum showed pseudo molecular ions at $\mathrm{m} / \mathrm{z} 515$ for $[\mathrm{M}+]$ ion. The ESI-positive mode mass spectrum showed pseudo molecular ions at $\mathrm{m} / \mathrm{z} 515[\mathrm{M}+\mathrm{Na}]+$ ion suggesting a molecular weight of 515 . Based on spectral analysis the compounds were identified as 3,3-di-O-methylellagic acid4-O--d-glucopyranoside portion with some little impurity.

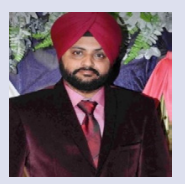

Gagan Shah: Is a Ph.D student at the IKG Punjab Technical University, Kapurthala, Punjab. He graduated in Bachelor of Pharmacy from Guru Nanak Dev University, Amritsar \& Master of Pharmacy in Pharmacognosy \& Natural Products from Punjabi University Patiala. His doctoral research focused on the evaluation of Anti-anxiety, anti-inflammatory activity and Antioxidant Activity of natural products as well as Standardization Parameters of medicinal Plants.

Cite this article: Shah G, Baghel US, Singh D. Isolation and Identification of Compounds from the Leaf Extract of Melaleuca alternifolia. Pharmacog J. 2017;9(6)Suppl:s52-s5. 